\title{
Controlled study of exclusion of dietary vasoactive amines in migraine
}

\author{
S A W SALFIELD, B L WARDLEY, W T HOULSBY, S L TURNER, A P SPALTON, \\ N R BECKLES-WILSON, AND S M HERBER
}

Department of Paediatrics, Rotherham District General Hospital, and Sheffield Children's Hospital

SUMmARY To assess the effects of dietary vasoactive amines in the aetiology of childhood migraine, 39 children were randomly allocated to either a high fibre diet low in these substances or a high fibre diet alone. Both groups of children showed a significant decrease in the number of headaches and there was no significant difference between the two groups.

Dietary vasoactive amines have not been shown in this study to influence childhood migraine. The improvement seen in both groups emphasises the need for a control diet in studies designed to show that dietary manipulation improves disease.

Migraine is a common problem that affects some $4 \%$ of schoolchildren between the ages of 7 and 15 and often causes considerable distress and disruption of school and social activities. ${ }^{\prime}$ The aetiology remains unknown and various dietary components and other stimuli have been considered to precipitate attacks in different individuals. Various foods contain vasoactive amines, ${ }^{2}$ and recent work has concentrated on biochemical idiosyncratic reactions to vasoactive amines ${ }^{3-5}$ and on food allergy ${ }^{6}$ as possible mechanisms for the suspected association between food intolerance and migraine.

Studies on the effect of vasoactive amines have produced conflicting results. Hannington's work in adults claimed to show that vasoactive amines were important precipitants of migraine, ${ }^{2-4}$ but Forsyth could not confirm this in children. ${ }^{5}$ These studies involved challenges with capsules that contained placebo or vasoactive amines but were not conducted by dietary modification in every day circumstances over several weeks.

Claims have been made for causal associations between food intolerance and an ever increasing number of diseases or exacerbation of diseases, but few of these have been substantiated by controlled trials. Because of the extensive publicity on food intolerances we believe that dietary manipulation may have a profound placebo effect, and consequently we performed a prospective controlled study of a diet low in vasoactive amines.

\section{Patients and methods}

All children included in the study were referred by their general practitioner or by another paediatrician to one or other of our children's outpatient clinics.

Migraine was defined as episodic headaches associated with nausea, vomiting, or visual disturbances when other diagnoses had been excluded. Patients with recurrent abdominal pain were not included unless they also suffered from migraine headaches. Children were excluded if they had previously tried dietary manipulations.

Two children had a history of epilepsy, three had asthma, and one had hay fever.

After medical consultation the dietitian obtained the dietary history and informed the parents of the nature of the trial. After enrolment the parents were given open access to the clinic to discuss any concern or difficulties. For the first eight weeks no dietary advice was offered and parents were asked to record all symptoms or signs in a standard diary given to

\section{Table 1 Foods excluded in diet $B$}

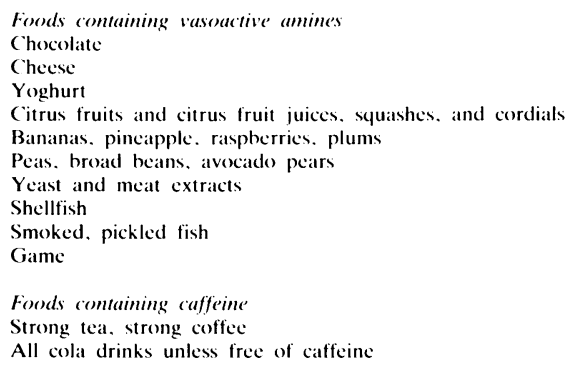


them. Children who had at least one migraine headache every two weeks were then randomly allocated to receive either a diet rich in fibre that did not exclude foods high in vasoactive amines (diet A) or the same high fibre diet that did exclude foods

Table 2 Reasons for excluding patients during study

\begin{tabular}{ll}
\hline Forms missing & 6 \\
Failure to return & 5 \\
Modifying diet themselves & 4 \\
Drugs prescribed by general practitioner & 3 \\
Doubtful diagnosis & 3 \\
Appendicitis & 1 \\
\hline
\end{tabular}

Table 3 Characteristics of the patients according to feeding regimen

\begin{tabular}{lll}
\hline & \multicolumn{2}{l}{ Feeding regimen } \\
\cline { 2 - 3 } & Diet A & Diet B \\
\hline Mean age (years) & $10 \cdot 33$ & $11 \cdot(18$ \\
Age range (years) & $3 \cdot 58-15 \cdot 25$ & $5 \cdot(18-15 \cdot 58$ \\
$\begin{array}{l}\text { Sex (M:F) } \\
\text { Family history of migraine }\end{array}$ & $12: 8$ & $12: 7$ \\
$\begin{array}{l}\text { Duration of history of migraine } \\
\text { (months) }\end{array}$ & 10 & 8 \\
\hline
\end{tabular}

high in vasoactive amines (diet B) for an eight week period. The foods forbidden during this time are listed in Table 1. Parents were asked to continue recording symptoms during the trial period.

A crossover method was not used as it was thought that the patients who improved on one diet would be reluctant to switch to another and compliance might be lost.

Eighty children were recruited to the initial assessment, of whom 61 were suitable for inclusion. Thirty nine of these children successfully completed the trial; the reasons for non-completion of the trial are summarised in Table 2 . The child and parents were seen by the dietitian four weeks after starting the diet and again four weeks later, when the trial was concluded. No patients received prophylactic treatment with drugs during this period, though they were encouraged to use simple analgesia to relieve headaches. The diet was discussed fully with the family and no suggestion was made that one diet was likely to be more effective than another.

Initially, a simple scoring system was used to grade the severity of the headaches and accompanying symptoms. As this correlated strongly with the number of headaches the latter, being a less subjective variable, was used in the final analysis.

Table $4 \%$ Improvement seen in patients with migraine given high fibre diet alone (diet A) or high fibre and low vasoactive amine diet (diet $B$ )

\begin{tabular}{|c|c|c|c|c|c|c|c|}
\hline \multicolumn{8}{|c|}{ Feeding regimen } \\
\hline \multicolumn{4}{|c|}{ Die' A } & \multicolumn{4}{|c|}{ Diet $B$} \\
\hline \multirow{2}{*}{$\begin{array}{l}\text { Case } \\
\text { No }\end{array}$} & \multicolumn{2}{|c|}{ No of attacks } & \multirow[t]{2}{*}{$\%$ Improvement } & \multirow{2}{*}{$\begin{array}{l}\text { Case } \\
\text { No }\end{array}$} & \multicolumn{2}{|l|}{ No of attacks } & \multirow[t]{2}{*}{$\%$ Improvement } \\
\hline & $\begin{array}{l}\text { Eight weeks } \\
\text { assessment }\end{array}$ & $\begin{array}{l}\text { Eight weeks } \\
\text { on diet }\end{array}$ & & & $\begin{array}{l}\text { Eight weeks } \\
\text { assessment }\end{array}$ & $\begin{array}{l}\text { Eight weeks } \\
\text { on diet }\end{array}$ & \\
\hline 1 & 27 & () & ) $1(x)$ & 1 & 6 & 0 & \multirow{3}{*}{$1(k)$} \\
\hline 2 & 6 & 1 & \multirow{2}{*}{\} $80-89$} & 2 & 9 & () & \\
\hline 3 & 5 & 1 & & 3 & 6 & () & \\
\hline 4 & 14 & 3 & \multirow{2}{*}{$7(1-79$} & 4 & 33 & 6 & \multirow{2}{*}{$80-89$} \\
\hline 5 & 4 & 1 & & 5 & 17 & 3 & \\
\hline 6 & 21 & 7 & \multirow{4}{*}{$601-69$} & 6 & 18 & 4 & \multirow{2}{*}{$7(1-79$} \\
\hline 7 & 5 & 2 & & 7 & 8 & 2 & \\
\hline 8 & 10 & 4 & & 8 & 8 & 3 & \multirow[t]{2}{*}{$6(1-69$} \\
\hline 9 & 43 & 17 & & 9 & 35 & 16 & \\
\hline 10 & 7 & 3 & \multirow{3}{*}{$5(1-59$} & 10 & 12 & 6 & \multirow[t]{2}{*}{$50-59$} \\
\hline 11 & 4 & 2 & & 11 & 12 & 6 & \\
\hline 12 & 6 & 3 & & 12 & 6 & 4 & \multirow{2}{*}{$30-39$} \\
\hline 13 & 15 & 9 & \multirow{2}{*}{$+11-49$} & 13 & 1.3 & 9 & \\
\hline 14 & 20) & 12 & & 14 & 7 & 5 & \multirow{3}{*}{$20-29$} \\
\hline 15 & 8 & 5 & \multirow{3}{*}{$311-39$} & 15 & 1.3 & 10 & \\
\hline 16 & 17 & 11 & & 16 & 15 & 12 & \\
\hline 17 & 25 & 17 & & 17 & 11 & 11 & \multirow{2}{*}{\} 0} \\
\hline 18 & 17 & 1.3 & $2(1-29$ & 18 & 4 & 4 & \\
\hline 19 & 8 & 14 & \multirow[t]{2}{*}{ Worse } & 19 & 30) & 42 & \multirow[t]{2}{*}{ ) Worse } \\
\hline 20 & 5 & 14 & & & & & \\
\hline Total & 267 & 1.39 & & & 263 & 143 & \\
\hline
\end{tabular}




\section{Results}

Of the 39 children who completed the trial, 20 were assigned to diet A and 19 to diet B. The two groups were similar in age, sex, family history of migraine, and duration of history of migraine (Table 3 ). Before starting the study two children assigned to the high fibre diet (A) were thought by their parents to have attacks provoked by food: in one case cheese was the suspected agent and in the other tomatoes. Four of the children on the low amine diet (B) were similarly suspected to have attacks precipitated by food: in all cases these were foods high in vasoactive amines.

There was a significant reduction in the number of migraine headaches in both groups and there was no significant difference between the two groups. Patients assigned to the low amine diet (B) had a mean (SD) number of headaches of 13.84 (9.25) during the trial. This dropped to $7.53(9.41)$ during the time they were on their diet $(p<0 \cdot 01)$ Sixteen of the 19 children had at least a $20 \%$ reduction in the number of attacks during this time and 10 of these had at least a $50 \%$ improvement. Patients assigned to a high fibre diet (A) had a reduction in the mean (SD) number of headaches from $13.35(10.09)$ to $6.95(5.84)$ during their time on the diet $(p<0 \cdot 01)$. Eighteen of the 20 children in this group had at least a $20 \%$ reduction in the number of attacks and 11 of these had at least a $50 \%$ improvement (Table 4).

\section{Discussion}

Previous studies that have assessed the role of vasoactive amines in the aetiology of childhood migraine have produced conflicting results. ${ }^{45}$ As far as we are aware, this is the first published controlled study in children that compares a diet low in vasoactive amines with a control diet. Our findings show that removing vasoactive amines from the diet had no greater effect in reducing the number of migraine attacks than giving sensible advice about a high fibre intake in this group of children with uncomplicated migraine not selected for a history of food sensitivity. Due to the small number who completed the trial we cannot exclude the possibility that there are a small number of children who have a genuine biochemical idiosyncracy to vasoactive amines.

The great improvement we found in many of our patients remains unexplained. In some it may have been due to reassurance to the parents and the child that the diagnosis was not more sinister. Many of the children were previously receiving a poor diet with irregular meals high in sugar and fat. Regular high fibre meals may have countered a tendency to hypoglycaemia ${ }^{8}$ but serial blood glucose measurements were not performed. It is possible that a high fibre intake protects against the absorption of dietary vasoactive amines, but we are not aware of any evidence to support this. In many the improvement was probably due to the placebo effect of prescribing changes to the diet.

Food allergy has recently been a focus of attention as an aetiological factor in childhood migraine. Studies of dietary manipulation without the use of control diets have reported improvement with the use of oligoantigenic diets. Egger et al reported a $93 \%$ relief of symptoms in a highly selected group of children with severe and complicated migraine treated with oligoantigenic diets. ${ }^{6}$ Although no control diet was used, a proportion of children were challenged in a double blind fashion with antigens and controls. They concluded that most children with severe frequent migraine have food allergy. Monro et al drew similar conclusions about adults. $^{7}$

In view of the findings of the present study we urge the use of a control diet in studies designed to show that exclusion of any dietary component or other dietary modifications improve disease, unless there is clear objective evidence that this is the case, as in conditions such as gluten enteropathy.

We thank the Trent Regional Research Fund for supporting this study.

\section{References}

1 Bille BO. Migraine in school children. Acta Paediatr Scand [Suppl] 1962;51:14-151.

2 Hannington E, Thompson RHS. Pressor amines in food. British Nutrition Foundation Bulletin 1973;259:28-34.

${ }^{3}$ Sandler M, Youdim MBH, Hannington E. A phenylethylamine oxidising defect in migraine. Nature 1974;250:335-7.

${ }^{4}$ Hannington E, Horn M, Wilkinson M. Further observations on the effects of tyramine. In: Cochrane AL, ed. Background to migraine. London: Heinemann, 1970:113-9.

${ }^{5}$ Forsyth WI, Redmond A. Two controlled trials of tyramine in children. Dev Med Child Neurol 1974;16:794-9.

6 Egger J, Carter CM, Wilson J, Turner MW, Soothill JF. Is migraine food allergy? Lancet 1983 ;ii:865-8.

${ }^{7}$ Monro J, Carim C, Brostoff $J$. Migraine is a food allergic disease. Lancet 1984;ii:719-21.

${ }^{8}$ Barlow CF. Headaches and migraine in childhood. Oxford: Blackwell Scientific/Spastics International Medical Publications, 1984:40-1.

Correspondence to Dr S A W Salfield, Rotherham District General Hospital, Moorgate Road, Oakwood, Rotherham S60 2UD, England.

Received 28 November 1986 